\title{
Input Data Acquisition Possibilities for Numerical Simulation of Drawing Process by means of the Contact-less Optical System and Thermo-camera
}

Jiri Sobotka, Pavel Solfronk, Michaela Kolnerova, David Korecek

Faculty of Mechanical Engineering, Technical University of Liberec. Studentská 1402/2, 46117 Liberec

Czech Republic.E-mail: jiri.sobotka@tul.cz,pavel.solfronk@tul.cz, michaela.kolnerova@tul.cz, david.korecek@tul.cz

Drawing process is generally influenced by many technological parameters (e.g. holding pressure, friction coefficient, etc.) and all of them should be considered for numerical simulation of such process. This paper deals with the possibilities how to determine one of the parameters that is quite difficult to be taken into account - magnitude of heat generated during forming process. In this case only heat generated by plastic deformation was determined, thus static tensile test at different loading rates was performed. Contact-less optical system ARAMIS and Thermo-camera FLIR SC660 was used to measure distribution of both plastic deformation and temperature on samples surfaces.

Keywords: Contact-less Measurement, Thermo-camera, Static Tensile Test, Formability, Numerical Simulation

\section{Introduction}

Quality of products after drawing process (so called stampings) is always a great interest of any producer. During the last years, a huge development was done especially in the pre-production phase due to application of many FEM as numerical simulations of this process. Accuracy of these numerical simulations strongly depends on input data quality. Nowadays, many parameters influencing stampings quality are already taken into account (e.g. stress-strain cures, yield criterions, friction, etc.), but some of them are still difficult to be involved into these software. And heat generated during forming process is one of them. $[1,2]$ Nevertheless, there are already software packages (e.g. PAM-STAMP), which now can involve this influence. Generally speaking, heat generated during metal forming process has two major sources plastic deformation and friction $[3,4]$. In this paper possible procedure how to measure temperature (as well as deformation) generated only by plastic deformation is shown - thus static tensile test was used. Heat generated from friction can be subsequently measured e.g. by strip drawing test and it will be topic of further research. The major aim of this paper was to show, how to determine temperature-deformation behavior of tested material, which can be (just as values or whole images) subsequently used at numerical simulation as input data to increase its accuracy. Briefly speaking, to give numerical simulation such input data that will results in good matching between its results and reality.

As a tested material, there was chosen low-alloy deepdrawing material commonly marked just as HX300 (complete abbreviation is HX300 LAD $100 \mathrm{MCO}$ ) of thickness $0.8 \mathrm{~mm}$. [5] It is material, that is quite commonly used in nowadays automotive industry. First of all, there was performed static tensile test and basic mechanical properties in dependence on load-rate are summarized in Tab. 1 and graphically shown as engineering stress-strain curves in Fig. 1 (left). Note that material revealed upper and lower yield strength. Own experiment was primarily planned to be performed both for load-rate $200 \mathrm{~mm} \cdot \mathrm{min}^{-1}$ and 400 $\mathrm{mm} \cdot \mathrm{min}^{-1}$ and it was also already done for both of them. However, measured values (both from thermo-camera and optical system ARAMIS) from $400 \mathrm{~mm} \cdot \mathrm{min}^{-1}$ weren't reliable due to low maximal data scanning frequency (frames per second) of these devices ( $30 \mathrm{fps}$ and $15 \mathrm{fps}$, resp.). For this load-rate should be used highspeed cameras in future research. So that is why in this paper was finally evaluated only temperature-deformation behavior of tested material HX300 for load-rate $200 \mathrm{~mm} \cdot \mathrm{min}^{-1}$.

Tab. 1 Basic mechanical properties of tested deep-drawing material HX300 for different loading rates

\begin{tabular}{|c|c|c|c|c|c|}
\hline $\begin{array}{c}\text { Deep-drawing material } \\
\text { HX300 LAD 100 MCO }\end{array}$ & \multicolumn{3}{|c|}{ Strength properties } & \multicolumn{2}{c|}{ Formability properties } \\
$\begin{array}{c}\text { Basic mechanical properties and } \\
\text { used load-rate }\left[\mathrm{mm} \cdot \mathrm{min}^{-1}\right]\end{array}$ & $\begin{array}{c}\text { Upper yield } \\
\text { strength } \\
\mathrm{R}_{\mathrm{eH}}[\mathrm{MPa}]\end{array}$ & $\begin{array}{c}\text { Lower yield } \\
\text { strength } \\
\mathrm{R}_{\mathrm{eL}}[\mathrm{MPa}]\end{array}$ & $\begin{array}{c}\text { Ultimate } \\
\text { strength } \\
\mathrm{R}_{\mathrm{m}}[\mathrm{MPa}]\end{array}$ & $\begin{array}{c}\text { Uniform } \\
\text { ductility } \\
\mathrm{A}_{\mathrm{g}}[\%]\end{array}$ & $\begin{array}{c}\text { Total } \\
\text { ductility } \\
\mathrm{A}_{80 \mathrm{~mm}}[\%]\end{array}$ \\
\hline $10 \mathrm{~mm} \cdot \mathrm{min}^{-1}$ & 403.0 & 376.7 & 431.4 & $\mathbf{1 8 . 6 9}$ & 29.52 \\
\hline $200 \mathrm{~mm} \cdot \mathrm{min}^{-1}$ & 428.1 & 388.4 & 446.4 & $\mathbf{1 6 . 5 8}$ & 26.56 \\
\hline $400 \mathrm{~mm} \cdot \mathrm{min}^{-1}$ & 435.7 & 392.2 & 449.0 & 16.71 & 29.68 \\
\hline
\end{tabular}




\section{Measured quantities and measuring devices lay-out}

The major aim of this paper was to set experimental measurement and to determine amount of heat generated just by the plastic deformation - dissipation of energy during plastic deformation. Eng. stress-strain curves of tested material in dependence on load-rate are shown in Fig. 1 (left). Note that higher load-rate $(10,200$ and finally $400 \mathrm{~mm} \cdot \mathrm{min}^{-1}$ ), the higher strength properties. Quite interesting behavior can be observed in light of total

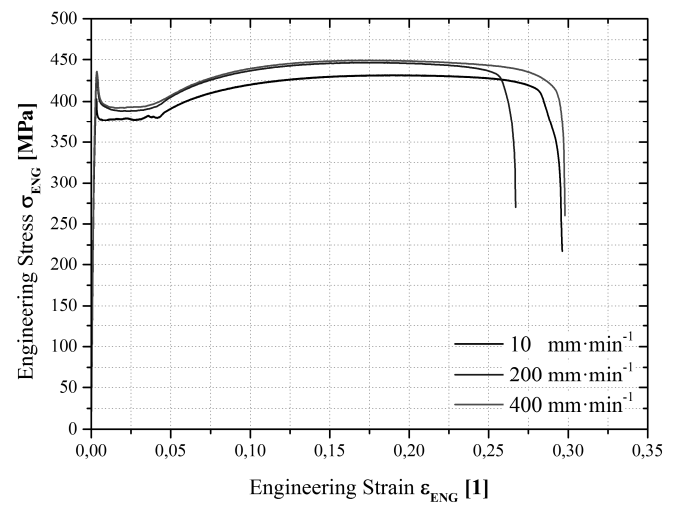

Fig. 1 Engineering stress-strain curves of tested material (left) and positioning of thermocouples TC1-5 (right)

In Fig. 2 the own arrangement (lay-out) of the experiment is shown. Static tensile test was performed with device TIRA test 2300 (no. 1). There was necessary to simultaneously used 3 different measuring devices thermo-camera FLIR SC660 (no. 2), PC for scanning data ductility $A_{80 \mathrm{~mm}}$, where under $400 \mathrm{~mm} \cdot \mathrm{min}^{-1}$ is such value similar to the lowest loading rate $10 \mathrm{~mm} \cdot \mathrm{min}^{-1}$ that is caused by heat generated just from plastic deformation. In Fig. 1 (right), the positioning of used D-type thermocouples (diameter $0.25 \mathrm{~mm}$ and welded by condenser welding in shielding gas of argon) on the sample surface is shown. There were used 5 TCs á $15 \mathrm{~mm}$ between them. TC3 was placed right in the middle of tested sample where the neck creation was expected. The same sample (just opposite side) was also measured by the thermo-camera FLIR SC660 and by optical contactless system ARAMIS.

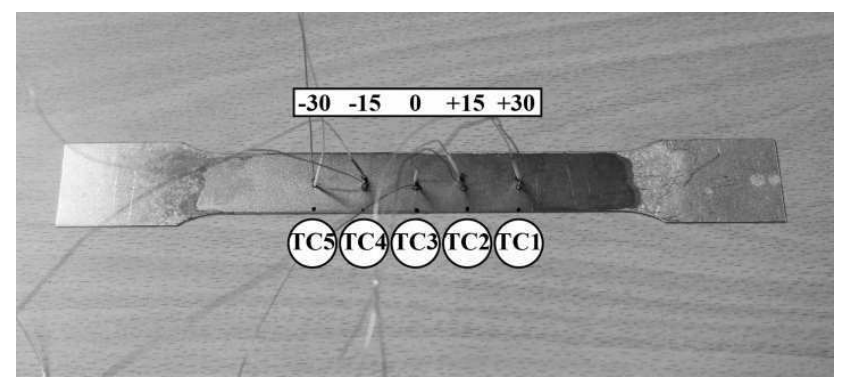

from thermocouples (no. 3) and finally optical system ARAMIS (no. 4) for contact-less deformation measurement. Preparation of such measurement was quite time consuming (cca 4,5 hrs).

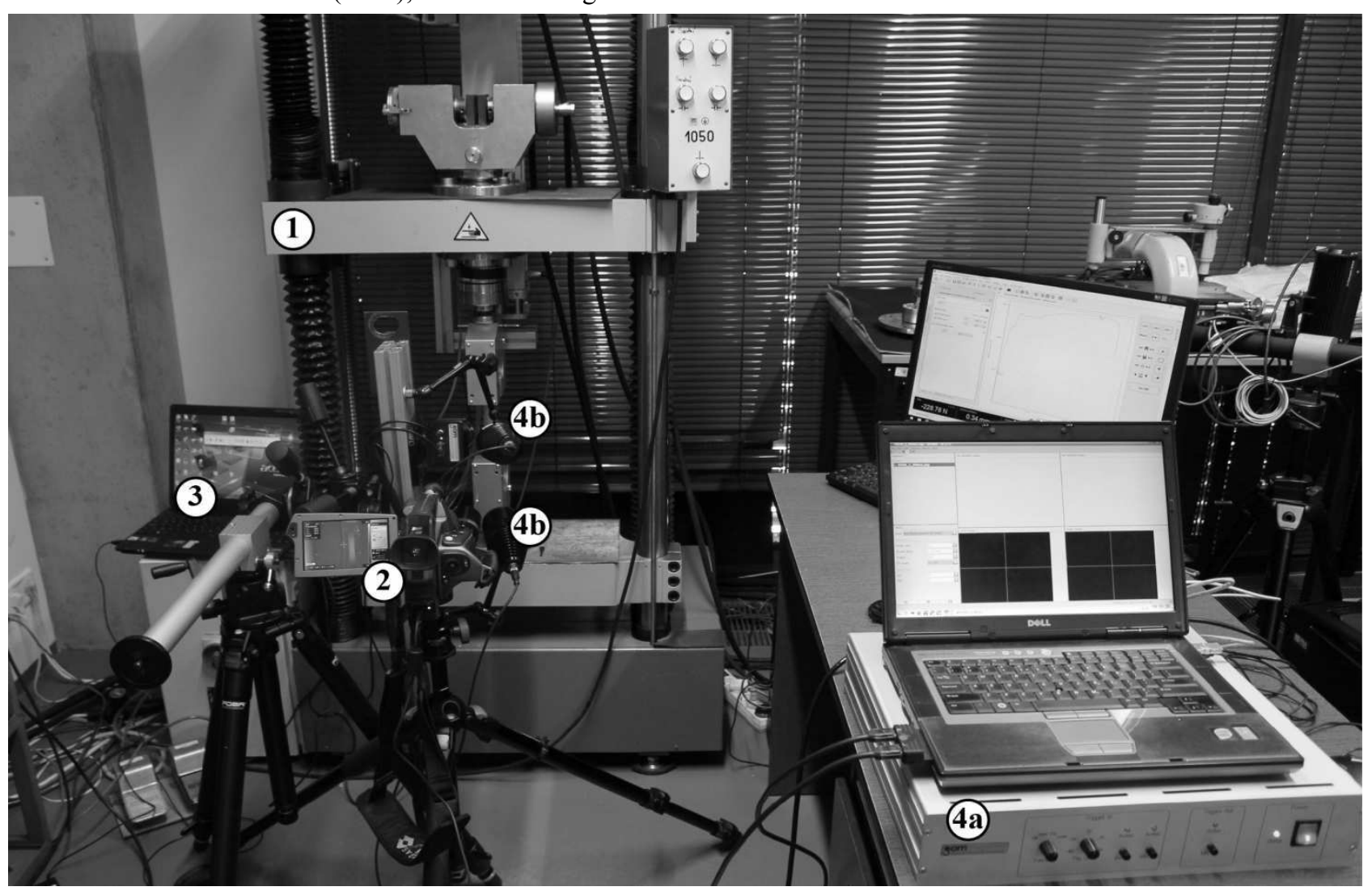

Fig. 2 Lay-out of the experiment: 1 - Device TIRA test 2300, 2 - Thermo-camera FLIR SC660, 3 - PC for scanning data from thermocouples, $4 a$-Optical system ARAMIS (PC and trigger), 4b-Optical system ARAMIS (cameras) 


\section{Temperature distribution during static tensile test measured by TCs and thermo-camera}

In this chapter results of TCs and thermo-camera (where emissivity was adjusted acc. to used TCs) from performed static tensile test under loading rate 200 $\mathrm{mm} \cdot \mathrm{min}^{-1}$ are summarized. Fig. 3 shows temperature courses measured by five TCs. Right part of this graph subsequently compares such course measured by TC3 (necking area) and data measured by the thermos-camera in the same location. It is obvious that there aren't any significant differences in heating area. Different situation can be observed after failure of sample. It seems that thermocouple of D-type is not suitable to measure temperature within this range in this zone (after failure). Nevertheless, it wasn't important for purpose of this paper, because it was interested only in the heating area (cca. till $7,5 \mathrm{sec}$ ), where result proved good matching between temperature values from TC 3 and thermo-camera and that is why there was also possible to compare the whole surface.

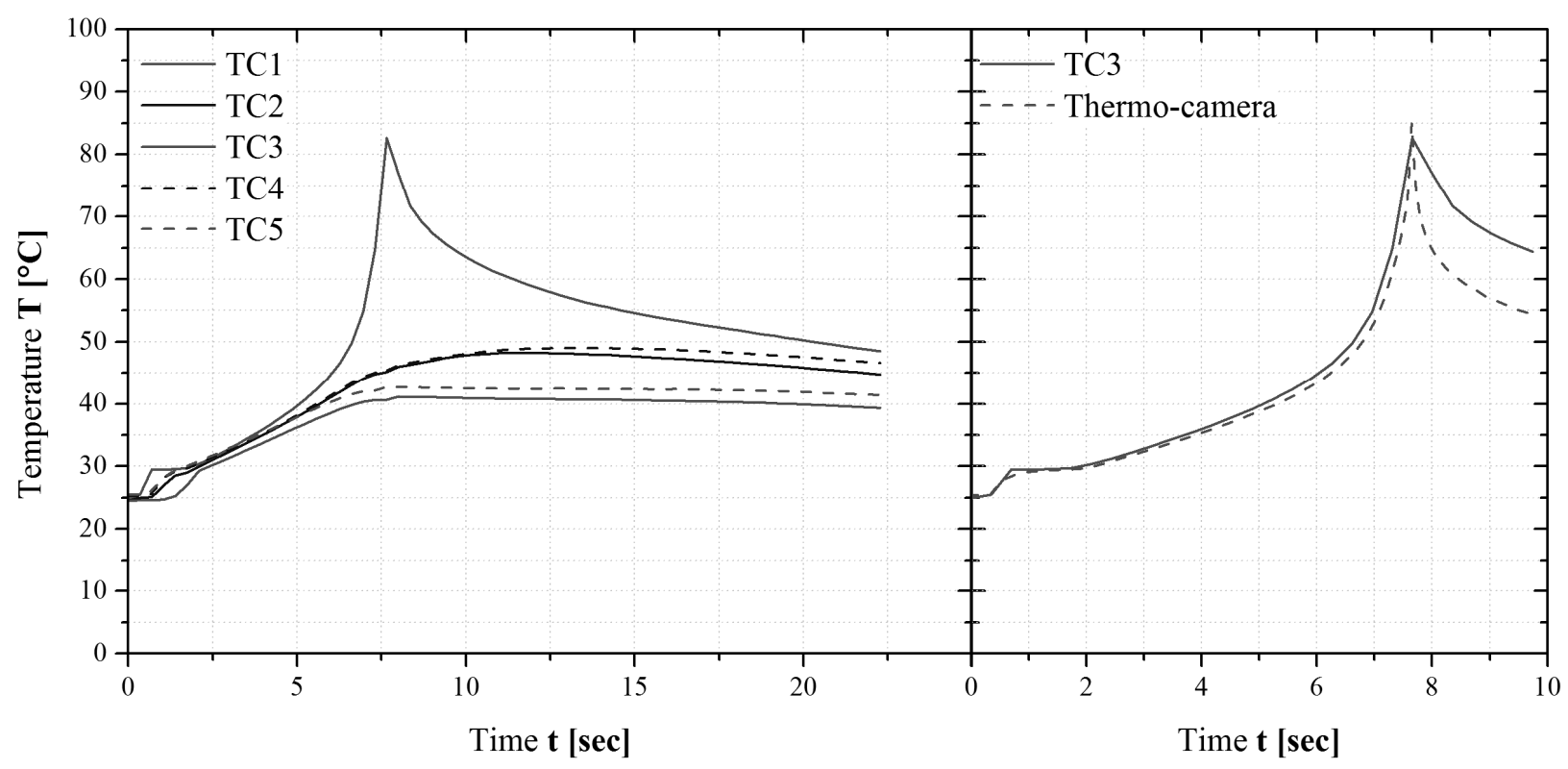

Fig. 3 Temperature courses vs time from TCs (left) and comparison of TC3 and thermo-camera in same point (right)

Due to the good matching between results from TCs and thermo-camera there was subsequently possible to done the own determination of heating rate $\Delta \mathrm{T}\left[{ }^{\circ} \mathrm{C} \cdot \mathrm{sec}^{-1}\right]$ in the monitored points marked as TC1 - TC5. Own $\Delta \mathrm{T}$ was taken as infinitesimal change of temperature with respect to time, thus differentiation of measured courses was performed. First of all was chosen suitable data range (from $R_{\mathrm{eL}}$ up to fracturee) with respect to time. These "cut curves" are shown in Fig. 4 (left). In light of research temperature-deformation behavior of this material it should

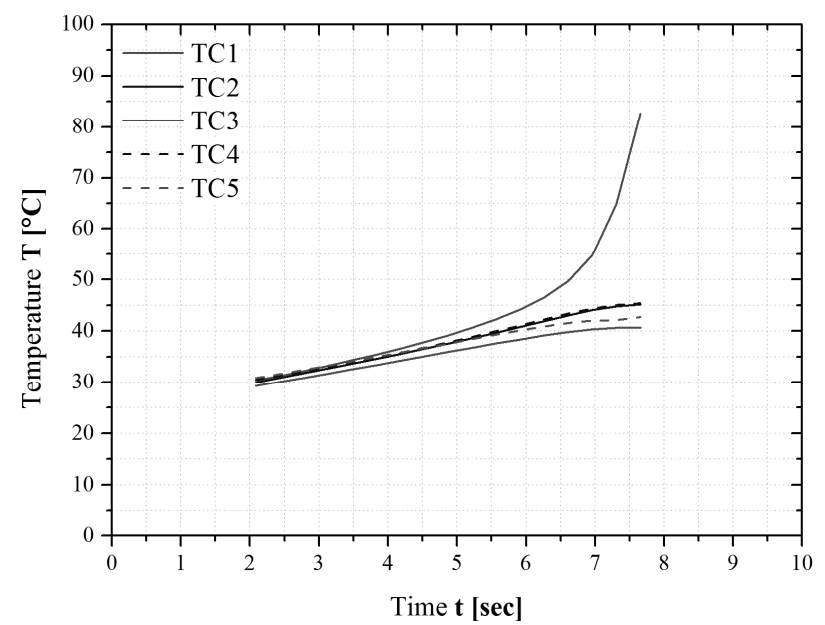

be quite interesting to perform detailed monitoring of initial part (cca. till $2 \mathrm{sec}$ ), but it wasn't main purpose of this article. Very important result is then shown in Fig. 4 (right) - namely heating rate vs time for monitored points TC1-5 which was performed via differentiation of measured curves. Beside the exact magnitudes of heating rates, there is obvious strong influence of necking creation. These results (together with thermo-camera ones) are very important for the numerical simulations.

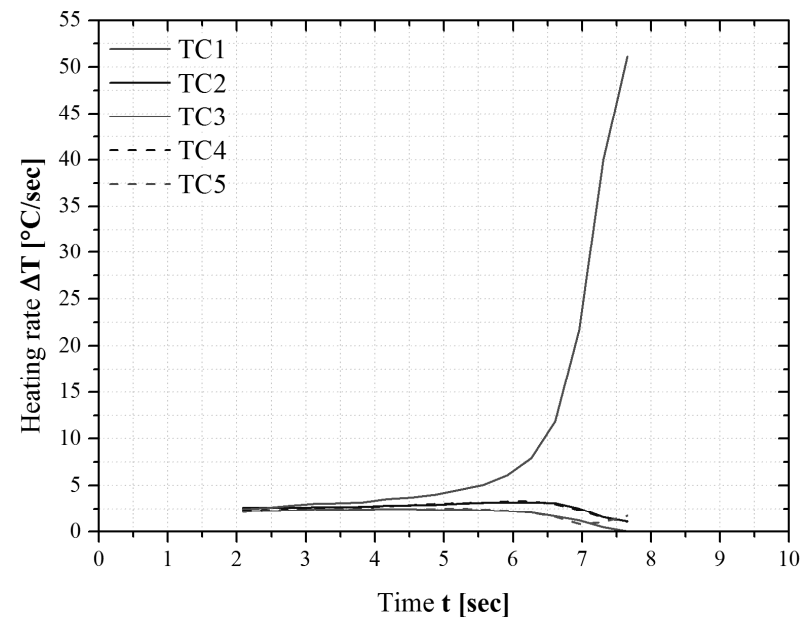

Fig. 4 "Cut curves" of temperature vs time for monitored points (left) and relevant heating rates in these points (right) 
As there was already mentioned before, the whole deformation process wasn't monitored only in the points by means of thermocouples, but it was scanned also by the thermo-camera FLIR SC660. Good matching between these measurements was shown in Fig. 3 (right). Own evaluation of the whole testing sample surface is digestedly shown in Fig. 5. Firstly, there is temperature distribution corresponding to initiation of plastic deformation (time very close to yield strength), where socalled slip band can be already seen - see Fig. 5 (right). After that there was time period, which corresponds to homogeneous temperature distribution and took approx. till achieving uniform ductility $\mathrm{A}_{\mathrm{g}}$. This is shown in Fig. 5 (middle). And finally there is shown moment right before fracture of sample - see Fig. 5 (left). One can see that this process (temperature distribution on the sample surface) closely matches to common deformation process during static tensile test, because in this case all deformation is transferred to heat generation. That is why it was monitored by so many devices in this experiment (thermocouples, thermo-camera and optical system ARAMIS). Future research should be focused on different material types as can be e.g. UHSS, stainless steels or aluminium alloys.

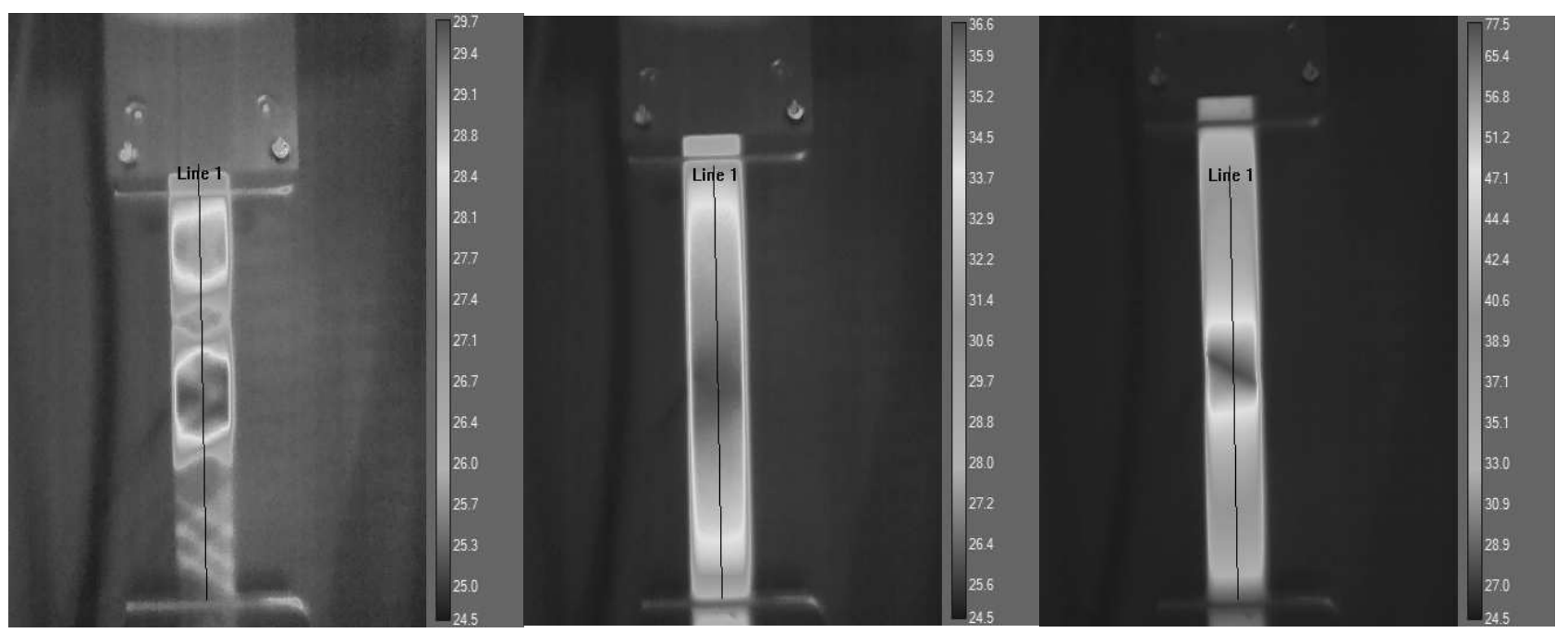

Fig. 5 Images from thermo-camera: slip bands (left), uniform ductility (middle) and right before fracture (right)

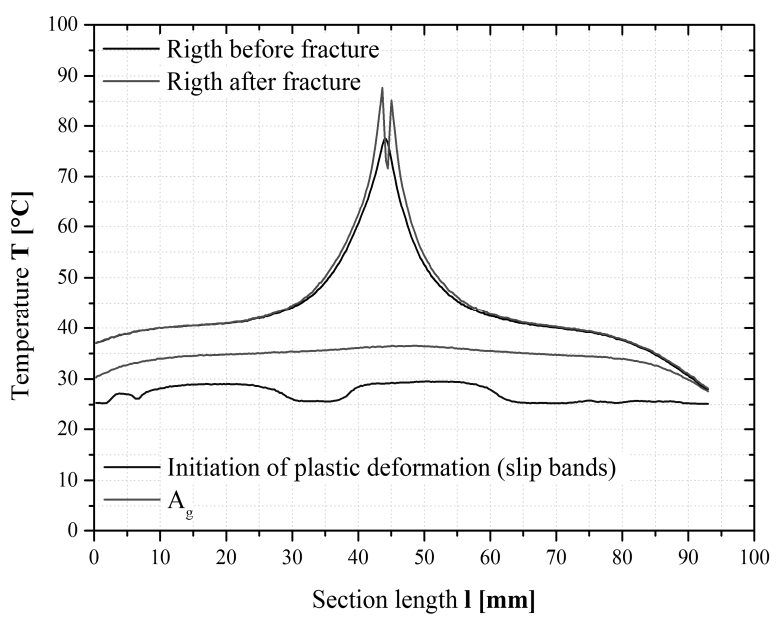

Fig. 6 Temperature distribution along section (Line 1) during static tensile test

Fig. 6 offers a detailed illustration of previous images from thermo-camera by means of line 1 along that are displayed exact temperature magnitudes. Moreover, there was also added moment right after fracture - red curve.
All these results were measured under loading rate 200 $\mathrm{mm} \cdot \mathrm{min}^{-1}$. As it was planned, there was also performed test under $400 \mathrm{~mm} \cdot \mathrm{min}^{-1}$. However, all scanning devices weren't able to acquire data with sufficient accuracy (due to low fps).

\section{Strain distribution during static tensile test measured by the contact-less optical system ARAMIS}

As there was already mentioned before, testing sample was also scanned by the contact-less optical system ARAMIS to determine true strain $\varepsilon_{\mathrm{T}}$ [1] distribution during static tensile test. Such "additional" measurement made own lay-out of measurement quite more complicated (see Fig. 2) and time consuming (together with thermo-couples, preparation of 1 sample took about $4.5 \mathrm{hrs}$ ). On the other hand, there was possible to measure true strain distribution on the same sample thus also in the same points TC1-5. Fig. 7 shows this true strain distribution in the moment right before fracture. There is also possible to see position of monitored points TC1-5 with relevant magnitude of $\varepsilon_{\mathrm{T}}$. 


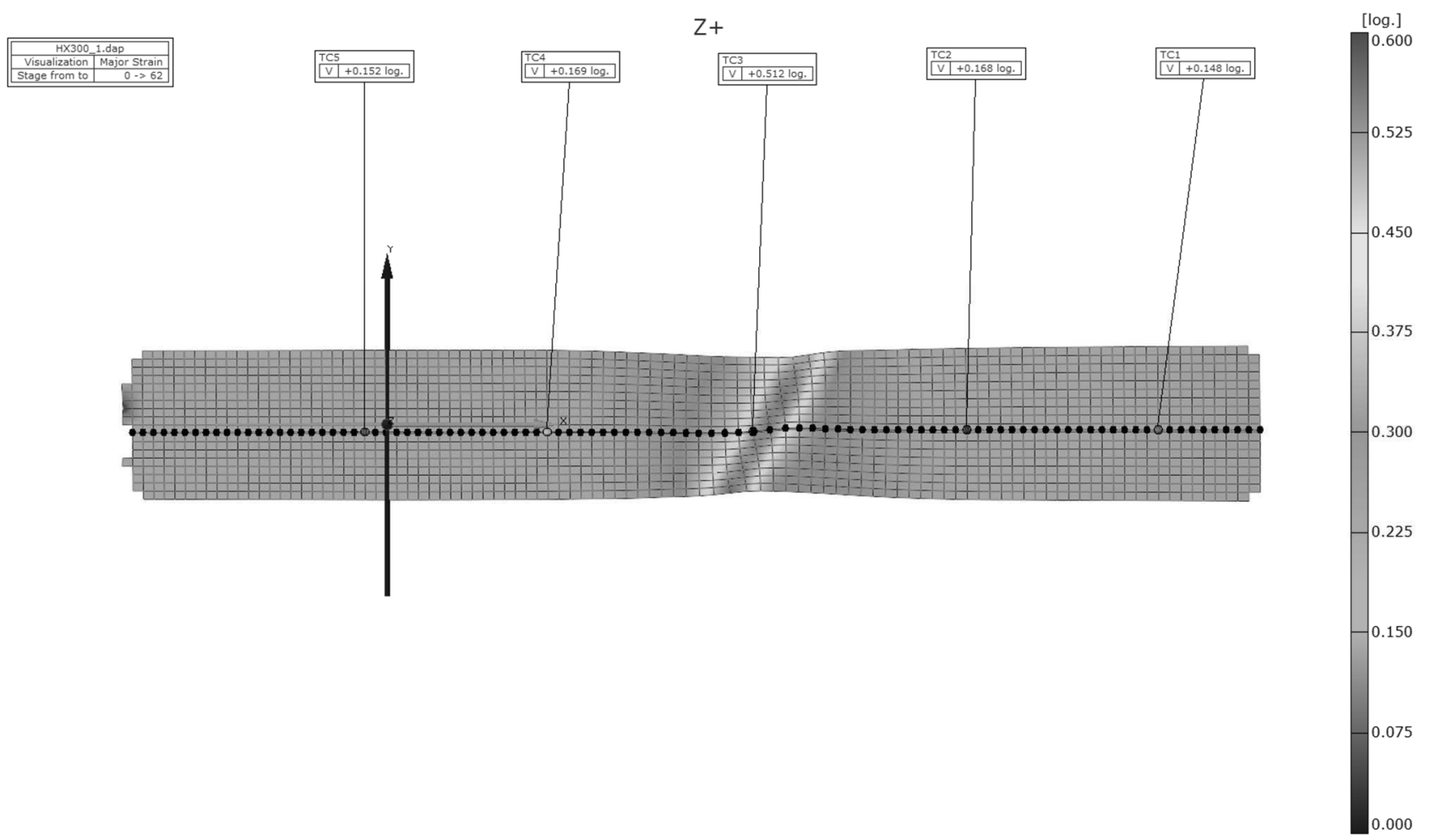

Fig. 7 Distribution of true strain $\varepsilon_{T}$ in the moment right before fracture and location of monitored points TC1-5

In Fig. 7, position of section along that was determined true strain distribution is also shown. These courses for different moments are subsequently displayed in Fig. 8 (left). Just as it was shown in Fig. 6 (temperature distribution along the same section), there are shown moments for initiation of plastic deformation (deformation right in the slip bands), uniform ductility $\mathrm{A}_{\mathrm{g}}$ (so homogeneous true strain distribution) and finally moment right before fracture with necking area. Fig. 8 (right) illustrates such deformation behavior by means of true strain course

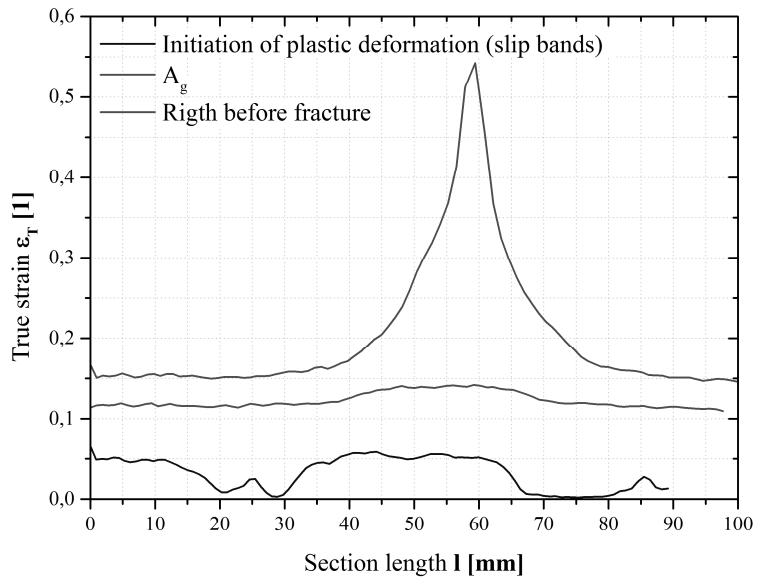

in the monitored points. Note again that TC3 was placed right in the necking area. This was probably the most important result obtained from the contact-less deformation measurement, because these curves were firstly compared with temperature-time curves (see Fig. 4) and then evaluated by their differentiation with respect time to obtain both heating and true strain rate (see Fig. 8), because these courses can offer the easiest way how to utilize these dependences in numerical simulations.

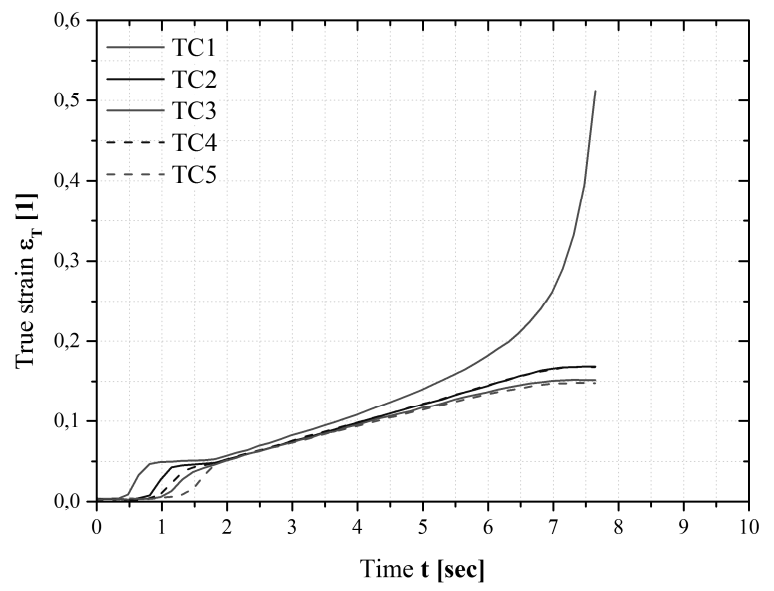

Fig. 8 Distribution of true strain $\varepsilon_{T}$ during static tensile test (left) and its course in monitored points TC1-5 (right)

\section{Conclusion}

The major aim of this paper was to demonstrate how to measure and acquire the most important data for amount of heat that is generated during forming process - to be specific just during plastic deformation. That is why there was performed static tensile test for tested material HX300 of thickness $0.8 \mathrm{~mm}$. Such values are these days incorporating into numerical simulations to increase their accuracy especially during production of car-body panels. These processes are greatly influenced 
also by heat generated from friction. However, this parameter was not monitored in this paper.

There were used both thermocouples and thermocamera to measure temperature changes during static tensile test. Moreover, there was applied also the contact-less optical system ARAMIS to simultaneously monitor strain distribution and thus also strain rate for the same sample. Firstly, there was proved good matching between results of thermocouples and thermo-camera (at least till sample fracture). Images from thermo-camera also made possible to monitor temperature distribution on the whole surface of tested material HX300 (see Fig. 5). These results are not very surprising - slip bands at the beginning of plastic deformation (yield strength), more or less homogeneous distribution under the ultimate strength and rapid increase of heat during necking till sample fracture, but they are very important to precisely characterize thermal behavior of tested material. These are very important input data to be used in numerical simulations, because they describe reality as heat generated from plastic deformation and numerical simulation has to reveal the same results. Mostly it is done as trial and error method until both results (simulation and reality ones) match.

In Fig. 9 are finally shown almost the most important results that were measured from static tensile test - heating rate $\Delta \mathrm{T}\left[{ }^{\circ} \mathrm{C} \cdot \mathrm{sec}^{-1}\right]$ and true strain rate $\Delta \varepsilon_{\mathrm{T}}\left[\mathrm{sec}^{-1}\right]$ in the same monitored points marked as TC1-5 (TC3 was placed in the necking area). These values (together with monitoring temperature and strain distribution on the sample surface) quite sufficiently describe thermal-deformation behavior of tested material and are going to be used as input data in numerical simulations. As was already mentioned before, the next step is to perform strip drawing test to characterize heat generated only from friction between tested strip and jaws - thus to perform common tribological testing.
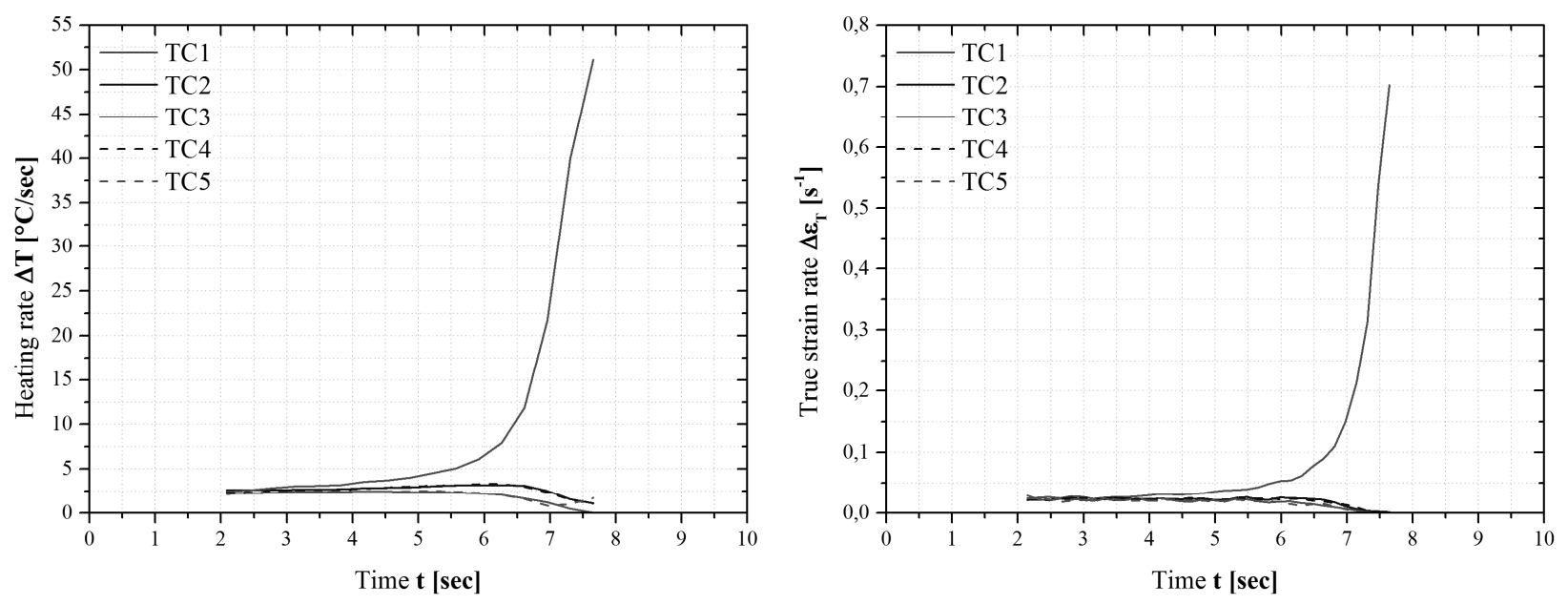

Fig. 9 Final graphical comparison of the most important results - rate of change both for temperature and true strain

\section{Acknowledgement}

This publication was written at the Technical University of Liberec (TUL) as part of the Student Grant Contest "SGS 21122" with the support of the Specific University Research Grant, as provided by the Ministry of Education, Youth and Sports of the Czech Republic in the year 2018.

\section{References}

[1] PÖHLANDT, K. (1989) Materials Testing for the Metal Forming Industry. Springer-Verlag, Berlin.

[2] KUHN, H., D. MEDLIN, ed. (2000). ASM

HANDBOOK Volume 8 - Mechanical Testing and Evaluation. ASM International, Materials Park.

[3] CHOVANEC, A., BREZNICKÁ A. (2017) Some Aspects of a Manufacturing Process. pp. 319325. Manufacturing Technology, Volume 17.

[4] ŤAVODOVÁ, M., KALINCOVÁ D. (2016) Improving the Quality of Castings Using Thermovision. pp. 268-273. Manufacturing Technology, Volume 16.

[5] DAVIES, G. (2003) Materials for Automobile Bodies. Butterworth-Heinemann, Oxford.

10.21062/ujep/259.2019/a/1213-2489/MT/19/1/144

Copyright (C) 2019. Published by Manufacturing Technology. All rights reserved. 